\title{
A Randomized Crossover, Pilot Study Examining the Effect of Acupuncture in the Management of Competitive Anxiety in Athletes
}

\author{
Mohammad Khojastefar ${ }^{1}$, Maryam Selk-Ghaffari ${ }^{1}$, Amir-Hossein Memari ${ }^{1}$, Farzin Halabchi ${ }^{2}$, \\ Tohid Seif-Barghi ${ }^{1,2, *}$ \\ ${ }^{1}$ Sports Medicine Research Center, Neuroscience Institute, Tehran University of Medical Sciences, Tehran, IR Iran \\ ${ }^{2}$ Department of Sports and Exercise Medicine, Tehran University of Medical Sciences, Tehran, IR Iran
}

Received October 7, 2020

Revised July 4, 2021

Accepted July 12, 2021

Correspondence to Tohid Seif-Barghi

Department of Sports and Exercise Medicine, Tehran University of Medical Sciences, Tehran, IR Iran

E-mail tohid_seif@yahoo.com
Background: Excessive competitive anxiety induces adverse effects on athletic performance and planning efficient management methods is crucial.

Objectives: We aimed to assess the effects of acupuncture on competitive anxiety.

Methods: In this cross-over study, 20 male soccer players under 21 years (U-21) were randomized equally into acupuncture or control groups. The acupuncture group received acupuncture on fifteen anxiety-related points and the control group received acupuncture on fifteen points unrelated to anxiety for thirty minutes. We measured the participants' resting heart rate and galvanic skin conduction and asked them to answer the Competitive State Anxiety Inventory-2 (CSAI-2) questionnaire at baseline and the end of the intervention.

Results: We detected a significant treatment effect in the cognitive anxiety level $(-1.05$ $\pm 0.91 ; p=0.02)$ but not in the somatic anxiety level $(-0.46 \pm 1.68 ; p=0.43)$, Sport Self-Confidence $(-1.06 \pm 2.21 ; p=0.11)$, heart rate $(0.20 \pm 2.2 ; p=0.93)$, and skin conductance $(-0.50 \pm 0.77 ; p=0.19)$.

Conclusion: Based on these results, acupuncture might decrease cognitive anxiety but might not affect somatic anxiety.

Keywords: Competitive anxiety, Athletes, Acupuncture

\section{INTRODUCTION}

Competitive anxiety is a critical psychological condition characterized by hyperarousal symptoms that occur in response to different levels of external or internal threats [1]. Competitive anxiety is the consequence of an imbalance assessment of environmental determinants and the athlete's ability to cope with threatening situations [1], which can leave a significant impression on the athlete's performance [2]. Competitive anxiety consists of cognitive, physiological, and behavioral components, such as somatic anxiety, cognitive anxiety, and self-esteem. Somatic anxiety is characterized by the individual's awareness of the physiological aspects of anxiety. The symptoms include increased heart and respiratory rate, sweating, and muscular tension. Cognitive anxiety comprises negative feelings, concerns, and prospects about undesired threatening situations [1]. Studies have indicated that competitive anxiety is significantly correlated with injury rate and performance deterioration [3].

Some degree of competitive anxiety may improve the athletic function, however, when uncontrolled, it may adversely impact athletic performance [4]. The strategies to manage competitive anxiety are a critical part of sports medicine [3]. Different methods, such as meditation, biofeedback, breath control, and cognitive-behavioral treatments (CBTs), are commonly used to manage the symptoms of anxiety in athletes [5]. However, these approaches require a continuous process and are timeconsuming [5]. The level of anxiety can be affected by an individual's serotonin level. The use of acupuncture to reduce the anxiety level was suggested because of its impact on the brain neurochemistry by promoting the release of neurotransmitters, such as serotonin, and increasing the level of encephalin in the central nervous system and plasma [6]. The use of acupuncture to manage general anxiety symptoms and preoperative and intraoperative anxiety is becoming of great 
value [7-9]. Since acupuncture is a low budget in an athletic environment, it could be evaluated as an alternative method in the prevention and management of competitive anxiety in athletes [10].

However, as far as we know, there is limited evidence about the effect of acupuncture on the anxiety level of competitive athletes in adult soccer. Considering the adverse effects of excessive competitive anxiety on an athlete's performance [3] and planning an efficient management method is crucial. In this trial, we aimed to assess the effect of acupuncture on competitive anxiety in a sample of athletes by assessing subjective and objective anxiety (e.g., heart rate and skin conduction) and physiological factors. We hypothesized that acupuncture intervention could decrease competitive anxiety levels and enhance athletic performance.

\section{MATERIALS AND METHODS}

The study was single-blinded, randomized, and placebocontrolled with a 2 -treatment, 2 -period $(2 * 2)$ crossover design. The study was registered at the Iranian Registry of Clinical Trials (IRCT20141115019948N3). Ethical approval for this trial was granted by the Medical Ethics Committee of the Tehran University of Medical Sciences (IR. TUMS. REC1395.2871). All the participants were asked to sign an informed consent form before the study with the responsibility of Tehran University of Medical Sciences. A detailed explanation of the study's objectives and intervention process was delivered to the participants. The project was conducted between April 2019 and June 2019 in the sports medicine clinic of Sports Medicine Research Center of Tehran University of Medical Sciences (TUMS), after providing informed consent.

\section{Participants}

The inclusion criteria were as follows: male, aged between 18 and 21 years old, history of at least one year of experience as an elite soccer player, and at least 3 weekly training sessions within the last year. The exclusion criteria included any history of acupuncture treatment, consumption of any medication, history of any psychological disorders (e.g., psychosis or depressive disorders), and the patient's request to leave the study. In this cross-over study, we recruited 20 male soccer players under 21 (U-21) from three different elite clubs in Tehran. Because individuals with different levels of environmental stress may have different responses to acupuncture, we recruited professional athletes with the same competitive level.

We conducted a pilot study three weeks before the intervention to familiarize the participants with the intervention process, including the skin conduction assessment and the acupuncture sessions. All the participants in the main study were involved in this pilot study. In the pilot study, acupuncture was performed in irrelevant points to assure the participants that the procedure was not painful.

\section{Randomization and blinding}

Participants were randomized by an automated computergenerated scheme in a 1:1 ratio. A research assistant with no responsibility in the project opened the sealed opaque envelopes and assigned the participants to the intervention (acupuncture) or control groups. The participants and outcome assessors were blind to the procedure but the acupuncturist was aware of the intervention. After considering a three weeks washout period, the intervention and control groups were exchanged (Fig. 1).

\section{Procedures}

The acupuncture group received acupuncture on fifteen points: MA-TF2 (bilaterally) [11], MA-TG2 (Tranquilizer) (bilaterally) [11], PC6 (bilaterally) [12], GV20 [13], EX-HN1 (Sishencong) [12], HT7 (bilaterally) [12], and BL62 (bilaterally) [12] 24 hours before the competition (Table 1). Following disinfecting the zone with alcohol, stainless steel dry needles (size $0.25 \mathrm{~mm} \times 25 \mathrm{~mm}$ and $0.18 \mathrm{~mm} \times 10 \mathrm{~mm}$ for body and ear points, respectively; SMC, Seoul, Korea) were inserted and kept in place for 30 minutes in a silent place where the participants were in a supine position. The control group (i.e., placebo) received acupuncture on points unrelated to anxiety: MA-TF6 (bilaterally), MA-ST5 (bilaterally), and eleven unrelated body points (Table 1, Fig. 2 and 3). The body points in the control group were fixed points defined based on anatomical description and unrelated to the Lung meridian. The acupuncture needles also remained in place for 30 minutes in the control group. A single registered acupuncturist expert (i.e., sports medicine specialist) with ten years of experience in acupuncture performed the acupuncture for both groups.

\section{Outcome measurements}

Before starting the evaluation process, each participant was asked to study a sheet and visualize its content in his mind. The sheet included common events in a competition, such as conflicts with the opposing team athletes, refereeing misjudgments, and the anxiety and stress in the competition field due to the possibility of losing the match. This imaginary process would assist to arouse competitive anxiety. Following this stage, we completed the pre-intervention measurements.

Before and one hour after each treatment session, we performed the physiological examinations, including the measure of resting heart rate (HR) and the participants completed galvanic skin conduction data and Competitive 


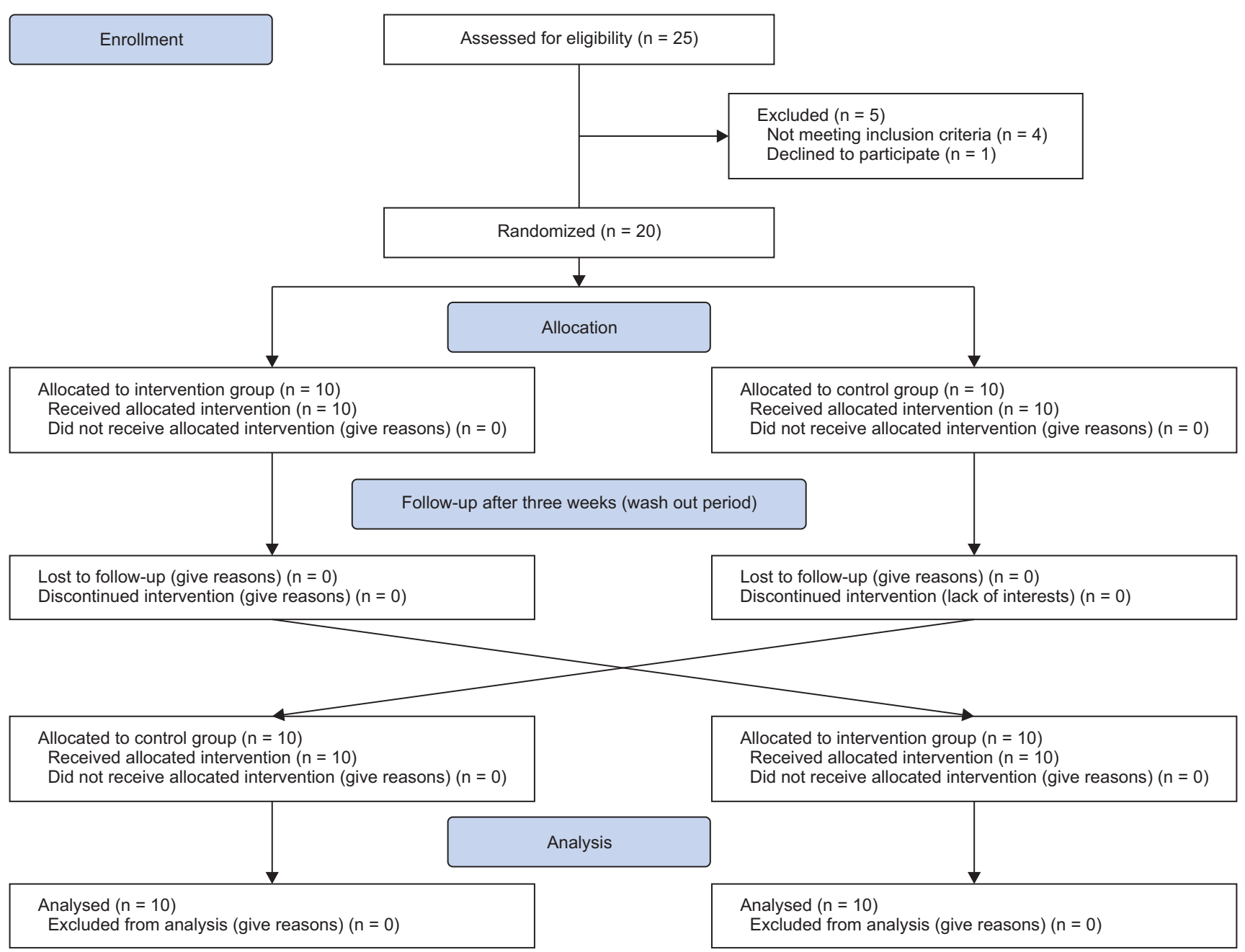

Fig. 1. Flow diagram of the study.

State Anxiety Inventory-2 (CSAI-2) questionnaire. Skin conductance and heart rate were indicative of the objective physiological condition of the participants. They were measured using a GSR_temp 2x-relaxation device (Procom Infiniti hardware from Thought Technology). The GSR temp 2x-relaxation device is a five-channeled biofeedback instrument that records skin conductance rate and heart rate via a multimodality encoder. The recorded information was transmitted to the processing computer and analyzed using the Biography software.

We measured the participants' skin conductance by attaching two small sensors around the distal tip of their index and ring fingers on the GSR_temp 2x-relaxation device. In this trial, the laboratory analysis was based on an average score of skin conductance recorded during 5 minutes of evaluation in a sitting position. Low-level voltage was applied to the skin to measure skin conductance. Skin conductance is affected by the activity level of the sweat glands. The sympathetic nervous system enhances the activity of the sweat glands and eventually, the skin conductance rate reflects the activity of the sympathetic nervous system. In a threatening situation, the activity of the sympathetic nervous system increases, which in turn also increases the sweat glands' activity and enhances skin conductance.

The heart rate of the participants was measured in a supine position following 10 minutes of rest based on the measurements performed by the GSR_temp 2x-relaxation device (ProComp Infiniti hardware from Thought Technology). The heart rate was calculated based on the time between the blood vessel pressure peaks.

The CSAI-2 is a questionnaire including 27 questions in the three domains of cognitive anxiety, somatic anxiety, and self-confidence [1]. It was used to assess the participants' psychological state before and one hour after the intervention. The questions are based on a 4-point scale ranging from 1 ("Not at all") to 4 ("Very much so"). An independent researcher conducted an organized, blinded assessment at baseline and the end of the intervention. 
Table 1. Description on anxiety related acupuncture points and unrelated points in control group
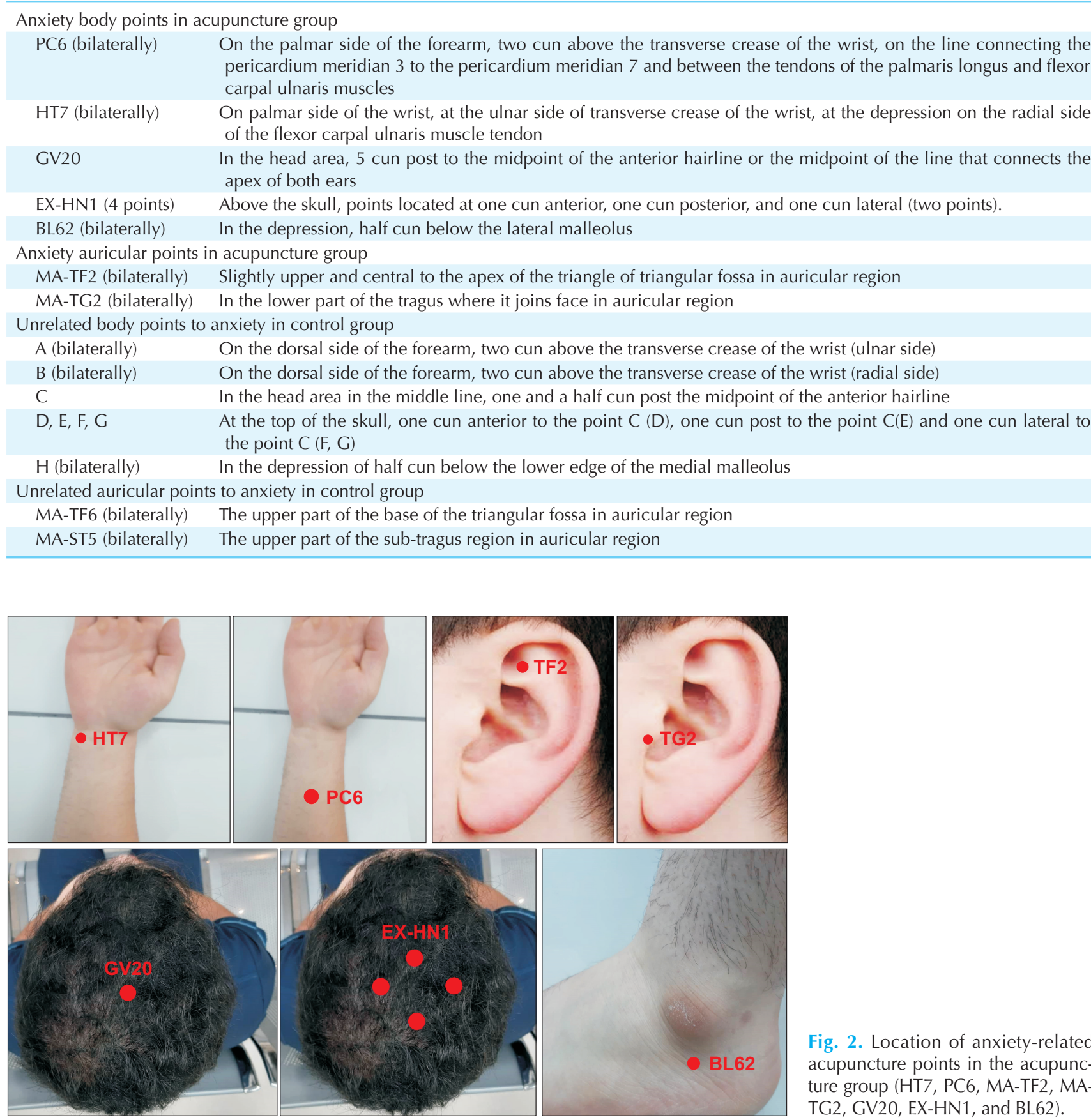

Fig. 2. Location of anxiety-related acupuncture points in the acupuncture group (HT7, PC6, MA-TF2, MATG2, GV20, EX-HN1, and BL62).

\section{Sample size}

The sample size was estimated as 10 individuals per group considering a 3-point difference in CSAI-2 score. We obtained the mean scores from an unconditional exact test in the pilot study. We considered a type I error ( $\alpha$ level) of 0.05 and a power of $80 \%$.

\section{Statistical analysis}

The variables, which are expressed as means (standard deviation), were evaluated for normal distribution. We analyzed the final results using a mixed-effect model of variance including the treatment, period, and carryover effects as a constant effect. We, then, assessed the individuals in a sequence for a random effect. The statistically significant values were set at less than 0.05 . We performed the analyses using the SPSS software version 20 for Windows (SPSS Inc., Chicago, IL, USA) and Stata version 13. 

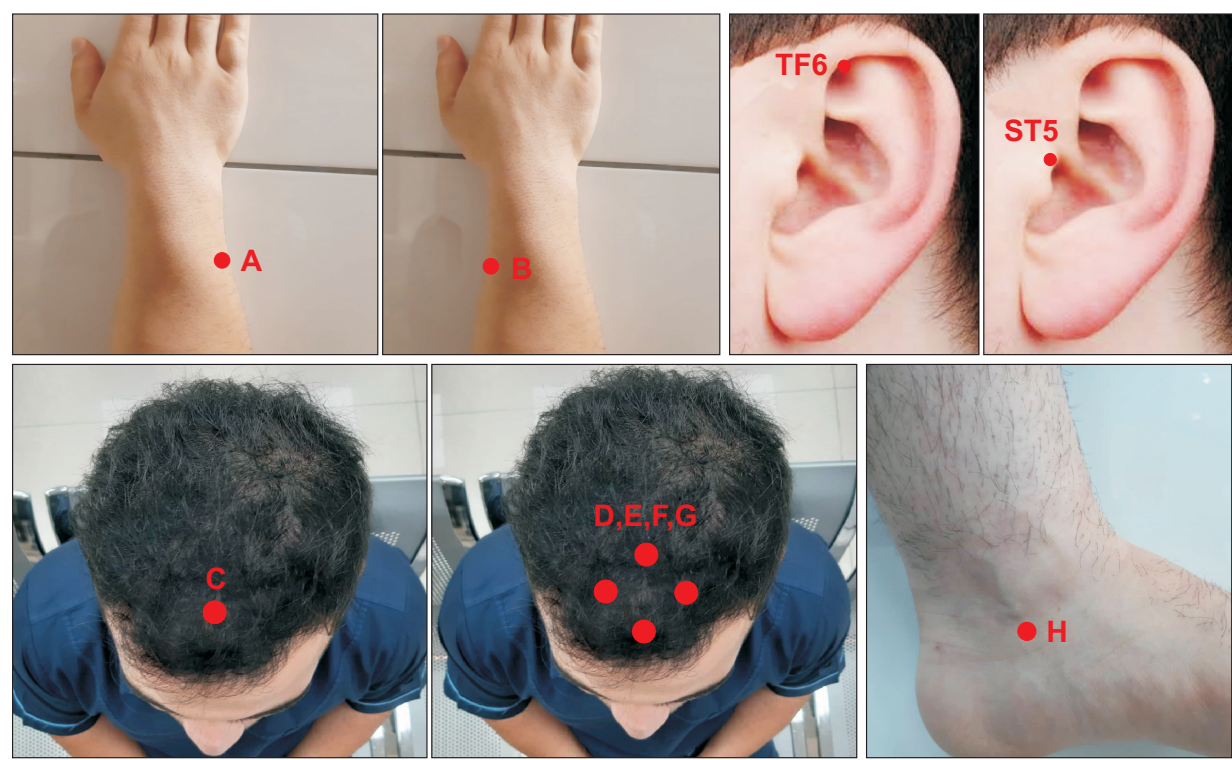

Fig. 3. Location of the unrelated acupuncture points in the control group (A, B, MA-TF6, MA-ST5, C, D, E, F, G, and $\mathrm{H})$.

Table 2. Demographical characteristics of participants at baseline

\begin{tabular}{|c|c|c|c|}
\hline Characteristics & $\begin{array}{c}\text { Sequence } A B \\
\text { (acupuncture- } \\
\text { control) }(n=10)\end{array}$ & $\begin{array}{l}\text { Sequence BA (control- } \\
\text { acupuncture) } \\
(\mathrm{n}=10)\end{array}$ & $p$-value \\
\hline Age (years) & $20(19-21)$ & $19(18-20)$ & 0.17 \\
\hline Height (cm) & $178(172-183)$ & $177.5(165.5-189.5)$ & 0.63 \\
\hline Weight (kg) & $65(56-74)$ & $72(61-83)$ & 0.08 \\
\hline $\begin{array}{r}\text { Body fat } \\
\text { percent }\end{array}$ & $13.8(11.5-16.1)$ & $11.6(8.3-14.9)$ & 0.08 \\
\hline $\begin{array}{l}\text { Professional } \\
\text { experience } \\
\text { (years) }\end{array}$ & $2(1-3)$ & $4(2-6)$ & 0.06 \\
\hline $\begin{array}{l}\text { Experience } \\
\text { aerobic } \\
\text { training } \\
\text { (years) }\end{array}$ & $2(0-4)$ & $3(2-4)$ & 0.06 \\
\hline $\begin{array}{l}\text { Experience } \\
\text { strengthening } \\
\text { training } \\
\text { (years) }\end{array}$ & $2(0-4)$ & $3(1-5)$ & 0.25 \\
\hline $\begin{array}{l}\text { Last serious } \\
\text { injuries } \\
\text { (numbers) }\end{array}$ & $0(-1$ to 1$)$ & $0.5(-0.5$ to 1$)$ & 0.85 \\
\hline
\end{tabular}

The values are expressed as mean (confidence interval 95\%).

\section{RESULTS}

\section{Participants' characteristics}

Among the 20 participants, we assessed the basic demographic and clinical characteristics of the study population (Table 2 and 3). There were no significant differences in the demographic, basic physiological, and psychological characteristics between the participants in the two sequences of the study at baseline (Table 2 and 3). The participants were allocated to the intervention and control group, randomly $(\mathrm{n}=$
Table 3. Clinical data of participants at baseline

\begin{tabular}{|c|c|c|c|}
\hline & $\begin{array}{c}\text { Sequence AB } \\
\text { (acupuncture- } \\
\text { control) }(n=10)\end{array}$ & $\begin{array}{l}\text { Sequence BA } \\
\quad(\text { control- } \\
\text { acupuncture }) \\
(\mathrm{n}=10)\end{array}$ & $p$ \\
\hline $\begin{array}{l}\text { Hear Rate Rest } \\
\text { (beat/minute) }\end{array}$ & $62(59.5-67.5)$ & $64.3(58.9-69.7)$ & 0.36 \\
\hline Somatic anxiety score & $14.5(9.8-19.2)$ & $12.9(8.8-17)$ & 0.49 \\
\hline Cognitive anxiety score & $18.6(13.1-24.1)$ & $18.4(13.1-23.7)$ & 0.94 \\
\hline $\begin{array}{l}\text { Sport self-confidence } \\
\text { score }\end{array}$ & $16.9(9.8-24)$ & $13.2(10.1-16.3)$ & 0.15 \\
\hline Skin conductance $(\mu \mathrm{m} / \mathrm{s})$ & $2.1(1.3-2.9)$ & $1.9(1-2.8)$ & 0.49 \\
\hline
\end{tabular}

The values are expressed as mean (confidence interval 95\%).

10 for the intervention group, $\mathrm{n}=10$ for the control group). After a three weeks washout period, the participants in the intervention and control groups were exchanged (Fig. 1).

\section{Changes in physiological characteristics}

The differences in physiological characteristics within and between the groups are illustrated in Table 4. We did not detect any treatment effect on heart rate and skin conductance (Table 5).

\section{Changes in psychological characteristics}

The differences in psychological characteristics within and between the groups are illustrated in Table 6. We detected a significant treatment effect on the participants' cognitive anxiety level $(p=0.02)$ but not on their somatic anxiety level and sport self-confidence (Table 6).

No adverse effect was reported following acupuncture in the intervention or control group. 
Table 4. Between groups and within groups changes of physiological characteristics

\begin{tabular}{|c|c|c|c|c|c|c|}
\hline & \multicolumn{3}{|c|}{ Sequence $A B$ (acupuncture- control) $(n=10)$} & \multicolumn{3}{|c|}{ Sequence BA (control- acupuncture) $(n=10)$} \\
\hline & $\begin{array}{l}\text { Intervention } \\
(\mathrm{Cl} 95 \%)\end{array}$ & $\begin{array}{l}\text { Control } \\
\text { (Cl 95\%) }\end{array}$ & ${ }^{* *} p$ & $\begin{array}{l}\text { Intervention } \\
\text { (CI 95\%) }\end{array}$ & $\begin{array}{l}\text { Control } \\
\text { (Cl 95\%) }\end{array}$ & $* * p$ \\
\hline \multicolumn{7}{|c|}{ Heart ate rest (pulse/min) } \\
\hline After treatment & $60.9(56-65.8)$ & $60.8(56-65.6)$ & 0.06 & $63.6(59-68.15)$ & $63.9(60.5$ to -67.2$)$ & 0.48 \\
\hline Mean Difference & $3(0.2-5.7)$ & $1.2(-1.6$ to 4.1$)$ & & $1.8(-2$ to 5.6$)$ & $0.4(-2.4$ to 3.2$)$ & \\
\hline${ }^{*} p$ & 0.007 & 0.21 & & 0.17 & 0.67 & \\
\hline \multicolumn{7}{|c|}{ Skin conductance $(\mu \mathrm{m} / \mathrm{s})$} \\
\hline After treatment & $2.1(1.6-3.1)$ & $2.1(0.42-3.6)$ & 0.06 & $2.4(0.4-4.3)$ & $1.4(0.6-2.2)$ & 0.07 \\
\hline Mean Difference & $0.8(0.4-1.2)$ & $0.1(-1.8$ to 2.1$)$ & & $1.1(0.4-1.7)$ & $0.5(-0.2$ to 1.2$)$ & \\
\hline${ }^{*} p$ & $<0.001$ & 0.87 & & 0.001 & 0.07 & \\
\hline
\end{tabular}

${ }^{*} p$-value after treatment versus baseline (within group differences).

${ }^{* *} p$-value of between group differences.

Table 5. The treatment effect, period effect and carryover effect of acupuncture versus control

\begin{tabular}{lcccccc}
\hline \multicolumn{1}{c}{ Outcome } & Treatment effect $(\mathrm{Cl} 95 \%)$ & $p$ & Period effect $(\mathrm{Cl} 95 \%)$ & $p$ & Carryover effect (Cl 95\%) & $p$ \\
\hline Heart rate rest & $0.20(-2.04$ to 2.4$)$ & 0.93 & $0.21(-4.74$ to 4.34$)$ & 0.84 & $-2.9(-6.42$ to 0.63$)$ & 0.1 \\
Skin conductance & $-0.50(-1.26$ to 0.27$)$ & 0.19 & $-0.98(-0.52$ to 2.48$)$ & 0.18 & $-0.17(-0.95$ to 1.29$)$ & 0.75 \\
Somatic anxiety & $-0.46(-2.12$ to 1.22$)$ & 0.43 & $-1.3(-4.96$ to 2.09$)$ & 0.58 & $1.05(-1.58$ to 3.68$)$ & 0.41 \\
Cognitive anxiety & $-1.05(-3.24$ to -1.15$)$ & 0.02 & $-4.90(-8.73$ to 1.07$)$ & 0.26 & $-1.05(-4.84$ to 2.74$)$ & 0.57 \\
Sport self confidence & $-1.06(-3.25$ to 1.15$)$ & 0.11 & $-2.3(-5.14$ to 0.54$)$ & 0.51 & $1.12(-2.08$ to 4.38$)$ & 0.46 \\
\hline
\end{tabular}

Table 6. Between groups and within groups changes of psychological characteristics

\begin{tabular}{|c|c|c|c|c|c|c|}
\hline & \multicolumn{3}{|c|}{ Sequence $A B$ (acupuncture- control) $(n=10)$} & \multicolumn{3}{|c|}{ Sequence BA (control- acupuncture) $(n=10)$} \\
\hline & Intervention (Cl 95\%) & Control (Cl 95\%) & ${ }^{* *} p$ & Control $(\mathrm{Cl} 95 \%)$ & Intervention (Cl 95\%) & ${ }^{* *} p$ \\
\hline \multicolumn{7}{|l|}{ Somatic anxiety score } \\
\hline After treatment & $12(9-15)$ & $13.1(9.2-17)$ & 0.08 & $11.4(8.1-14.7)$ & $11.6(8.3-15)$ & 0.21 \\
\hline Mean Difference & $1.2(-0.03$ to 2.4$)$ & $1.2(-0.6$ to 3$)$ & & $0.4(-0.4$ to 1.2$)$ & $1.3(11-15)$ & \\
\hline${ }^{*} p$ & 0.01 & 0.07 & & 0.17 & 0.09 & \\
\hline \multicolumn{7}{|c|}{ Cognitive anxiety score } \\
\hline After treatment & $13.3(10.3-16.3)$ & $16.8(12-21)$ & 0.002 & $15.4(11-18.8)$ & $16.8(12.8-20.8)$ & 0.02 \\
\hline Mean Difference & $2.7(0.7-4.7)$ & $1.8(-1.2$ to 4.8$)$ & & $0.9(-0.3$ to 2.1$)$ & $1.6(-0.1$ to 3.3$)$ & \\
\hline${ }^{*} p$ & 0.02 & 0.11 & & 0.04 & 0.02 & \\
\hline \multicolumn{7}{|l|}{ Self-confidence score } \\
\hline After treatment & $12.2(8.2-15.2)$ & $13.8(11-17.6)$ & 0.07 & $11.5(9.5-13.5)$ & $12.2(10.2-14.2)$ & 0.06 \\
\hline Mean Difference & $0.4(-1.6$ to 2.4$)$ & $3.1(-0.7$ to 6.9$)$ & & $0.3(-0.1$ to 0.7$)$ & 1 (-0.7 to 2.33$)$ & \\
\hline${ }^{*} p$ & 0.57 & 0.03 & & 0.08 & 0.04 & \\
\hline
\end{tabular}

${ }^{*} p$ after treatment versus baseline (within group differences).

${ }^{* *} p$ of between group differences.

\section{DISCUSSION}

In this study, the use of acupuncture decreased the participants' cognitive anxiety level but did not show any effect on the somatic anxiety level, sport self-confidence, HR, and skin conductance compared to the control group.

In a study by Shu et al., [10] the cognitive state anxiety level following acupuncture was significantly reduced compared to the sham group among professional athletes. However, the changes in somatic anxiety levels and self-confidence were not significant between the groups [10]. In a study by Zarei et al., [14] the cognitive and somatic anxiety of young athletes decreased following acupuncture but their self-confidence was not affected. Based on the Martens anxiety theory, anxiety is a multi-dimensional phenomenon [4]. Competitive anxiety consists of psychological and physiological components that include cognitive and somatic aspects as well as self-confidence. These components have a 
moderate relationship to one another and change differently depending on the sports events [4]. The cognitive aspect of competitive anxiety consists of negative feelings, concerns, and prospects relating to the performance. The somatic aspect includes the physiological responses to stressful situations and threats (e.g., increased heart rate and sweating) [1]. Previous studies indicated that the cognitive aspect of anxiety displayed a significant negative linear equation with competitive performance [4]. However, an inverted U-shaped curvilinear relationship is proposed between increasing levels of somatic anxiety and athletic performance. Somatic anxiety to a certain level will improve function [4]. Hardy et al. declared that low to moderate levels of cognitive anxiety combined with high levels of the somatic aspect of anxiety will improve competitive performances [4]. Considering Hardy et al. theory and our trial results showing that acupuncture decreased the cognitive aspect of anxiety but did not affect the somatic anxiety levels, acupuncture might be an effective alternative treatment in the management of competitive anxiety. However, further studies are required to make definite judgments.

In a study by Zarei et al., [14] the skin conductance in young athletes decreased significantly following acupuncture $(p<0.001)$. However, the changes in heart rate following acupuncture were not significant $(p=0.06)$. Acupuncture is a multi-dimensional and complicated process with many local and central effects. For example, muscle tension is reduced and the plasma levels of serotonin increase following acupuncture sessions, which can lead to sedation and decreased anxiety. Similar changes are detected in brain tissue [6]. Acupuncture may also reduce the expression of glutamate and its related receptors, which can also promote significant effects on anxiety [15]. In our study acupuncture did not show any effect on somatic anxiety, HR, and skin conduction rate. This could be because the somatic anxiety level, HR, and skin conductance were not increased at baseline. Baseline HR and skin conductance were in normal ranges and they might not be affected by acupuncture. Additionally, our observation that the physiologic aspects of anxiety, such as HR and skin conductance, did not significantly change, is in accordance with the fact that we also did not observe any significant changes in the levels of somatic anxiety.

One of the limitations of this study is that our pilot study was conducted on male soccer players. Future research involving both genders and other sports disciplines is recommended to generalize the results. Our trial also included only one single session of acupuncture and no sham group. Future studies should include multiple sessions of treatment and a sham group. The imaginary process was conducted before the first assessments. To avoid any time effect, the imaginary process should also be performed before the second assessment. Finally, our assessments were performed following the acupuncture session after exposure to an imaginary process. Further studies should assess the effect of acupuncture following a real competition to evaluate the practical impact of acupuncture. Further studies in all sports disciplines, gender, age groups, and larger athletic populations are recommended to determine the impact of acupuncture on competitive anxiety.

\section{CONCLUSIONS}

In conclusion, acupuncture might decrease cognitive anxiety levels but might not affect somatic anxiety. Acupuncture might assist athletes to reduce the adverse effects of competitive anxiety on their performance. However, further studies are mandated to propose acupuncture as an effective treatment method for competitive anxiety in athletes.

\section{ETHICAL APPROVAL}

Ethical approval for this trial has been granted by the Medical Ethics Committee of the Tehran University of Medical Sciences (IR. TUMS.REC1395.2871).

\section{FUNDING}

This study was supported by the Sports Medicine Research Center, Neuroscience Institute, Tehran University of Medical Sciences.

\section{ACKNOWLEDGEMENTS}

We appreciate the Tehran University of Medical Sciences for the support.

\section{AUTHORS' CONTRIBUTIONS}

MKh \& FH \& TS: Conceptualization, Methodology, Investigation (Quality assessment), MKh \& AM: Investigation (Data collection and extraction), MS: Writing - Original Draft, Writing - Review \& Editing, AM \& TS: Formal analysis, FH \& TS \& AM \& MS \& MKh: Review \& Editing, Approval of final version.

\section{CONFLICT OF INTEREST}

The authors declare no conflict of interest. 


\section{ORCID}

Mohammad Khojastefar, https://orcid.org/0000-0002-3741-996X

Maryam Selk-Ghaffari, https://orcid.org/0000-0001-9960-6990

Amir-Hossein Memari, https://orcid.org/0000-0002-8302-1821

Farzin Halabchi, ～https://orcid.org/0000-0002-3005-6190

Tohid Seif-Barghi, https://orcid.org/0000-0001-7791-2372

\section{REFERENCES}

1. Craft LL, Magyar TM, Becker BJ, Feltz DL. The relationship between the Competitive State Anxiety Inventory-2 and sport performance: a meta-analysis. J Sport Exerc Psychol 2003;25(1): 44-65.

2. Woodman T, Hardy L. The relative impact of cognitive anxiety and self-confidence upon sport performance: a meta-analysis. J Sports Sci 2003;21:443-57.

3. Ford JL, Ildefonso K, Jones ML, Arvinen-Barrow M. Sportrelated anxiety: current insights. Open Access J Sports Med 2017;8:205-12.

4. Chamberlain ST, Hale BD. Competitive state anxiety and selfconfidence: intensity and direction as relative predictors of performance on a golf putting task. Anxiety Stress Coping 2007; 20:197-207.

5. Rumbold JL, Fletcher D, Daniels K. A systematic review of stress management interventions with sport performers. Sport Exerc Perform Psychol 2012;1:173-93.

6. Cabýoglu MT, Ergene N, Tan U. The mechanism of acupuncture and clinical applications. Int J Neurosci 2006;116:115-25.

7. Li M, Xing X, Yao L, Li X, He W, Wang M, et al. Acupuncture for treatment of anxiety, an overview of systematic reviews. Complement Ther Med 2019;43:247-52.

8. Ma R, Luo D, Liu Y, Lu L, Xu S, Wu Q, et al., eds. Acupuncture for generalized anxiety disorder: a systematic review. 2016 8th International Conference on Information Technology in Medicine and Education (ITME), December 23-25, 2016, Fuzhou, China. Piscataway: IEEE, 2016.

9. Wright KD, Stewart SH, Finley GA, Buffett-Jerrott SE. Prevention and intervention strategies to alleviate preoperative anxiety in children: a critical review. Behav Modif 2007;31:52-79.

10. Shu S, Zhan M, You YL, Qian XL, Li CM, Zhou CL, et al. Wrist-ankle acupuncture (WAA) for precompetition nervous syndrome: study protocol for a randomized controlled trial. Trials 2015;16:396.

11. Wang SM, Peloquin C, Kain ZN. The use of auricular acupuncture to reduce preoperative anxiety. Anesth Analg 2001;93:117880 , table of contents.

12. Pilkington $\mathrm{K}$, Kirkwood G, Rampes $\mathrm{H}$, Cummings $\mathrm{M}$, Richardson J. Acupuncture for anxiety and anxiety disorders--a systematic literature review. Acupunct Med 2007;25:1-10.

13. Isoyama $D$, Cordts EB, de Souza van Niewegen AM, de Almeida Pereira de Carvalho W, Matsumura ST, Barbosa CP. Effect of acupuncture on symptoms of anxiety in women undergoing in vitro fertilisation: a prospective randomised controlled study. Acupunct Med 2012;30:85-8.

14. Zarei S, Shayestehfar M, Memari AH, SeifBarghi T, Sobhani V. Acupuncture decreases competitive anxiety prior to a competition in young athletes: a randomized controlled trial pilot study. J Complement Integr Med 2017;14:20150085.

15. Tu CH, MacDonald I, Chen YH. The effects of acupuncture on glutamatergic neurotransmission in depression, anxiety, schizophrenia, and Alzheimer's disease: a review of the literature. Front Psychiatry 2019;10:14. 